\title{
Erratum to: Chimpanzees (Pan troglodytes) accurately compare poured liquid quantities
}

\author{
Michael J. Beran
}

Published online: 18 March 2010

(C) Springer-Verlag 2010

\section{Erratum to: Anim Cogn}

DOI 10.1007/s10071-010-0314-0

In the "Methods" section of Experiment 1, the specific quantities of fruit juice used were erroneously reported. The correct quantities used were 10, 20, 30, 40, 50, and
$60 \mathrm{ml}$, and these were the quantities represented by the terms 1 through 6 units used throughout the remainder of the paper. All liquids were poured from syringes with a maximum capacity of $60 \mathrm{ml}$, and they were poured at a rate of $10 \mathrm{ml} / \mathrm{s}$. These errors do not affect any of the results or conclusions of the paper.

The online version of the original article can be found under doi:10.1007/s10071-010-0314-0.

M. J. Beran ( $₫)$

Language Research Center, Georgia State University,

University Plaza, Atlanta, GA 30303, USA

e-mail: mjberan@yahoo.com 